\title{
Qual a sexualidade do livro didático de inglês? Novos letramentos e ensino de línguas na contemporaneidade
}

Elio Marques de Souto Júnior,

Universidade Federal do Rio de Janeiro

\begin{abstract}
Resumo
Este artigo objetiva investigar como as sexualidades são abordadas no livro didático de inglês. A análise será baseada na teoria bakhtiniana (BAKHTIN, 2004), nos construtos da gramática visual de Kress e Van Leeuwen (2006) e na teoria queer (LOURO, 2004) (MISKOLCI, 2012) (RUFFOLO, 2009).
\end{abstract}

Palavras-chave: livro didático, Bakhtin, teoria queer.

\begin{abstract}
This paper aims at investigating how sexualities are addressed in English textbooks. The analysis will be based on bakhtinian theory (BAKHTIN, 2004), on the constructs of visual grammar (KRESS and VAN LEEUWEN, 2006) and on queer theory (LOURO, 2004) (MISKOLCI, 2012) (RUFFOLO, 2009).
\end{abstract}

Keywords: textbook, Bakhtin, queer theory.

\section{INTRODUÇÃO}

$\mathrm{Na}$ contemporaneidade, as posições de gênero e sexualidade se multiplicaram, tornando as classificações tradicionais insuficientes para dar conta dos novos modos de subjetivação (LOURO, 2001, 2004). As fronteiras, pois, vêm sendo continuamente atravessadas, subvertendo a lógica binária sobre a qual o pensamento ocidental se alicerça (DERRIDA, 2004).

A sociedade é caracterizada por uma cultura falocêntrica de dominação masculina, cujo objetivo é moldar comportamentos de acordo com um ideal viril heterossexual e homofóbico (BOURDIEU, 2003). A escola, através das práticas pedagógicas e curriculares, reproduz essa ideia (JUNQUEIRA, 2012). Assim, qualquer traço de feminilidade deve ser rejeitado, a fim de garantir a perpetuação da heteronormatividade (JUNQUEIRA, 2009). 
O currículo escolar visa normalizar e normatizar a sexualidade, fabricando sujeitos sexuados, generificados e heterossexualizados (JUNQUEIRA, 2012). Desse modo, a escola ensina e permite a homofobia (LOURO, 2004). Ademais, o silêncio eloquente dos/as professores/as perpetuam os comportamentos discriminatórios, na medida em que se omitem em relação à homofobia (CASTRO, ABRAMOVAY e SILVA, 2004).

Como a linguagem é o meio pelo qual o preconceito é expresso (CASTRO, ABRAMOVAY e SILVA, 2004), a aula de línguas constitui um espaço privilegiado na problematização da sexualidade, pois nela os significados são negociados e as identidades (re)construídas nas interações discursivas, nas quais os sujeitos se engajam (MOITA LOPES, 2002).

Da mesma forma, identidades são marcadas no e pelo livro didático (LD) que, por sua vez, dissemina a ideologia dominante (SCHYERL, 2012) e, consequentemente, privilegia a heterossexualidade como única forma de o sujeito expressar sua sexualidade (LOURO, 2004).

Este estudo, pois, compreende o LD como um documento de identidade (SILVA, 2003a) repleto de discursos, que permitem que identidades sejam (re)construídas e negociadas (MOITA LOPES, 2002). Ademais, tendo em vista a importância que as questões acerca da sexualidade adquiriram no campo educacional, e o fato de que o Programa do livro didático aponta a isenção de estereótipos e discriminações de orientação sexual como um dos critérios para a seleção do LD (BRASIL, 2011), este artigo busca investigar quais sexualidades são abordadas em três atividades da unidade quatro do segundo volume do livro Prime (DIAS, JUCÁ e FARIA, 2010a), destinado ao ensino de inglês no segundo ano do Ensino Médio.

$\mathrm{O}$ artigo está organizado em quatro seções. A primeira versará sobre os construtos teóricos da teoria queer (BUTLER, 2003; LOURO, 2004; MISKOLCI, 2012) como uma forma de desnaturalizar a compreensão tradicional das categorias de gênero e sexualidade. Em seguida, na segunda seção, os conceitos bakhtinianos de dialogismo, polifonia e gênero discursivo (BAKHTIN, 2003; 2004) serão estudados. Na terceira seção, algumas considerações acerca da contemporaneidade (FRIDMAN, 2000), da globalização (KUMARAVADIVELU, 2006a) e seu impacto no ensino de línguas estrangeiras (KUMARAVADIVELU, 2006b) e do LD no contexto brasileiro 
(CORACINI, 1999; PINTO e PESSOA, 2009) serão feitas. Na última seção, os conceitos anteriormente discutidos serão utilizados na análise das atividades do LD.

\section{TEORIA QUEER: UMA POÉTICA DA TRANSGRESSÃO}

A teoria queer propõe uma nova forma de pensar as categorias de gênero e sexualidade para além dos essencialismos e binarismos (LOURO, 2004; MISKOLCI, 2012; RUFFOLO, 2009). Uma noção central na teoria queer é a de heteronormatividade que "seria a ordem sexual do presente, na qual todo mundo é criado para ser heterossexual, ou - mesmo que não venha a se relacionar com o sexo oposto - para que adote o modelo da heterossexualidade em sua vida" (MISKOLCI, 2012, p. 15). Instaurase, portanto, uma norma sexual compulsória que visa o controle dos sujeitos sexualizados.

Ao enfatizar o fato de a sexualidade ser construída histórica e discursivamente, Foucault (2001) argumenta que

\footnotetext{
A partir do século XVI, a "colocação do sexo em discurso", em vez de sofrer um processo de restrição, foi, ao contrário, submetida a um mecanismo crescente de incitação; que as técnicas de poder exercidas sobre o sexo não obedeceram a um princípio de seleção rigorosa mas, ao contrário, de disseminação e implantação das sexualidades polimorfas (FOUCAULT, 2001, p. 17).
}

Dessa forma, Foucault deixa clara a relação entre discurso, saber e poder que permitem o controle dos corpos e dos prazeres.

No século XIX, o discurso jurídico e médico-psiquiátrico cria a espécie do sujeito homoerótico e, ao produzir um saber sobre essa sexualidade herética, classifica o homoerotismo como desvio, doença, perversão e sinal da degradação do ser humano. $\mathrm{O}$ sujeito homoerótico, pois, passa a ser compreendido a partir da sua sexualidade, ou seja, "nada daquilo que ele é, no fim das contas, escapa à sua sexualidade. Ela está presente nele todo: subjacente a todas as suas condutas" (FOUCAULT, 2001, p. 43).

Baseada na teoria performativa da linguagem de Austin, que afirma que a linguagem cria a realidade através de atos reiterativos, Butler $(2001,2003)$ concebe o gênero como performativo, destacando que "a performatividade não é, assim, um ato singular, pois ela é sempre uma reiteração de uma norma ou conjunto de normas" (BUTLER， 2001, 
p. 167). Portanto, a nomeação dos corpos materializa o gênero, o que culmina no fato de que ninguém nasce homem ou mulher, mas tornam-se um ou outro.

A materialização do corpo a partir da existência de pênis ou vagina permite a inserção na cultura através do gênero inteligível masculino ou feminino. Para Butler (2003), "gêneros inteligíveis são aqueles que, em certo sentido, instituem e mantêm a relação de coerência e continuidade entre o sexo, gênero, prática sexual e desejo" (BUTLER, 2003, p. 38 [grifo no original]). Contudo, o gênero inteligível deve estar a serviço da matriz heterossexual.

\section{A TEORIA DIALÓGICA DE BAKHTIN}

Para Bakhtin (2004), a linguagem é um fenômeno sócio-histórico, ou seja, ela é dependente do contexto. A real substância da língua é constituída "pelo fenômeno social da interação verbal, realizada por meio da enunciação ou das enunciações. A interação verbal constitui, assim, a realidade fundamental da língua” (BAKHTIN, 2004, p. 123). Portanto a intersubjetividade antecede a subjetividade. O diálogo, pois, é condição para a produção de enunciados e, consequentemente, para a construção do significado.

A linguagem é eminentemente ideológica e o ser se reflete e se refrata no signo ideológico, o que permite que ele seja responsivo aos enunciados. Tal fato é caracterizado pelo "confronto de interesses sociais nos limites de uma só e mesma comunidade semiótica" (BAKHTIN, 2004, p. 46). Cada enunciado está repleto de vozes em relação hierárquica que estão sempre em conflito. Desse modo, por meio do signo ideológico nas interações verbais, os sujeitos constroem a si mesmos e aos outros.

A língua, seja na modalidade oral ou escrita, está presente em todas as esferas da vida social. A interação verbal se dá através de gêneros discursivos que são tão variados quanto os contextos de comunicação (BAKHTIN, 2003). Assim, os enunciados são materializados por meio de gêneros discursivos, que são formas diferentes de uso da linguagem. Estes gêneros possuem três dimensões indissociáveis: o conteúdo temático, que é o assunto ideologicamente investido, a construção composicional, que se refere aos elementos da estrutura textual e o estilo, que diz respeito às escolhas linguísticas (BAKHTIN, 2003). 


\section{O LIVRO DIDÁTICO NA CONTEMPORANEIDADE}

A contemporaneidade trouxe grandes mudanças e transformações para a sociedade, principalmente, no que diz respeito à cultura e ao comportamento humano (FRIDMAN, 2000). O discurso da contemporaneidade rejeita o caráter essencialista da cultura e das identidades sociais, vistas como fragmentadas, contraditórias e fluidas, questionando, pois, a noção do sujeito cartesiano unificado, coerente e racional (MOITA LOPES, 2002).

Um dos aspectos mais importantes da contemporaneidade é a globalização, e uma das suas principais características é a compressão das dimensões espaço-temporais, devido ao avanço das tecnologias de informação e comunicação (KUMARAVADIVELU, 2006a). Evidencia-se, pois, a emergência de um mundo global, onde as fronteiras nacionais vêm desaparecendo, o que tem consequências em todas as esferas sociais, a saber, econômica, política, cultural e educacional.

O processo da globalização trouxe mudanças na vida social no que diz respeito às tecnologias de informação e comunicação e, principalmente, no ensino de línguas estrangeiras (KUMARAVADIVELU, 2006a, 2006b). O advento dos Estados Unidos como super potência mundial fez com que o inglês se tornasse a língua da comunicação internacional, permitindo, assim, que culturas e países distantes entre si pudessem se comunicar (KUMARAVADIVELU, 2006a). Com base no conceito de glocalização (ROBERTSON apud KUMARAVADIVELU, 2006a), Kumaravadivelu (2006b) afirma que a compreensão do global permite que os/as alunos/as sejam capazes de pensar sua realidade de forma crítica e reflexiva, o que reflete nos materiais didáticos.

Material didático é "qualquer coisa usada para ajudar alunos/as de língua a aprender" (TOMLINSON, 2011, p. XIII) e "que apresente ou informe acerca da língua a ser aprendida" (TOMLINSON, 2011, p. XIV), podendo ser LDs, CD-roms, DVDs, etc. No contexto brasileiro, o LD é amplamente utilizado nas escolas (CORACINI, 1999).

O LD possui um papel central no processo de ensino/aprendizagem de línguas e, muitas vezes, é a "única fonte de consulta e de leitura dos professores e dos alunos" (PINTO e PESSOA, 2009, p. 79). O LD, então, influencia o que e como se ensina, constituindo um recurso importante na prática pedagógica (CORACINI, 1999).

Além de legitimar o trabalho docente, o $\mathrm{LD}$ é o único meio pelo qual tanto 
professores/as e alunos/as têm acesso ao conhecimento. Desta feita, os significados presentes no LD veiculam verdades tidas como absolutas, que não devem ser questionadas. Destacando seu caráter autoritário, Coracini (1999) afirma que o LD caracteriza uma "educação castradora" na qual "só há uma interpretação possível para os fatos e o mundo, enfim, uma educação que silencia, discrimina, reforça o centro e o justifica" (CORACINI, 1999, p. 12). Dessa forma, os significados presentes no LD estão sempre a serviço do poder dominante visto que o discurso não é neutro, mas representa uma visão de mundo particular.

A linguagem não só representa a realidade, mas também a constitui (FAIRCLOUGH, 2001). De fato, "o discurso constitui os objetos de conhecimento, os sujeitos e as formas sociais do eu, as relações sociais e as estruturas conceituais" (FAIRCLOUGH, 2001, p. 64). Nessa perspectiva, destaca-se a natureza social do discurso, que é o meio pelo qual os sujeitos agem no mundo, construindo a si mesmos e aos outros (MOITA LOPES, 2002). Como a linguagem é atravessada por relações de poder e pela ideologia, ela acaba por legitimar uns sujeitos e exclui outros.

O discurso instaura e sustenta relações de dominação que são marcadas por uma assimetria entre os atores sociais (THOMPSON apud SCHYERL, 2012). Desta feita, a estrutura hierárquica e binária da sociedade privilegia as identidades sociais, que seguem a norma, e marginaliza aquelas que não se conformam com o padrão estabelecido de normalidade (BUTLER, 2003; LOURO, 2004). Cria-se, pois, uma dicotomia entre identidade e diferença que vai reforçar atos discriminatórios (SILVA, 2003b).

A identidade e a diferença são social, cultural e simbolicamente construídas, estando "em uma estreita relação de dependência" (SILVA, 2003b, p. 74) e, por isso, "são mutuamente determinadas" (SILVA, 2003b, p. 76). Ademais, ambas são resultados de atos linguísticos que, ao nomeá-las, as cria. De fato, a identidade carrega o traço do que ela não é, ou seja, da diferença. Portanto, identidade e diferença não estão em oposição, mas são complementares.

No LD, não só a linguagem verbal constrói identidades, mas também a visual, destacando, assim, a importância dos elementos visuais na construção do significado (CALANTZIS e COPE, 2012; KRESS e VAN LEEUWEN, 2006). Em uma sociedade altamente semiotizada, os textos são constituídos, na maioria das vezes, por vários sistemas 
semióticos, a saber, oral, escrito, visual etc., sendo, pois, chamados de textos multimodais (CALANTZIS e COPE, 2012). Segundo Rojo (2012), a imagem, como prática social e veículo de significado, vem sendo negligenciada pela escola, o que tem repercussões na formação de sujeitos críticos e reflexivos. De fato, não basta apenas ser letrado na linguagem verbal, mas, para exercer a cidadania de forma plena, os sujeitos precisam ser capazes de compreender outros modos de significação (KRESS e VAN LEEUWEN, 2006).

\section{A ANÁLISE DA SEXUALIDADE NO LIVRO DIDÁTICO DE INGLÊS}

Em 2004, o Governo Federal criou o Programa Brasil sem Homofobia, com vistas a promover a cidadania da comunidade homoerótica. O documento ressalta a formação de equipes para avaliar os livros didáticos e eliminar os aspectos discriminatórios dos mesmos. Da mesma forma, o Guia do livro didático do PNLD (BRASIL, 2011) afirma que a coleção deve ser "isenta de estereótipos e preconceitos [...] de orientação sexual" (BRASIL, 2011, p. 16). Todavia, os LDs, ao silenciarem as sexualidades homoeróticas, contribuem na perpetuação da homofobia.

O livro Prime 2, segundo o "Manual do professor" (DIAS, JUCÁ e FARIA, 2010b), busca promover o letramento crítico. Consoante essa perspectiva, "ensinar significa promover ações educativas para que os alunos vejam fatos e situações sob diferentes pontos de vista [...], assumam uma posição ética frente às diferenças $\mathrm{e}$ aprendam sobre si próprios e sobre os outros" (DIAS, JUCÁ e FARIA, 2010b, p. 6) [grifo adicionado]). Todavia, as sexualidades homoeróticas não são abordadas de forma problematizadora.

A unidade quatro, intitulada "Love matters" ("O amor importa"), inicia por duas imagens de casais (fig.1), um jovem e outro idoso se beijando (DIAS, JUCÁ e FARIA, 2010a, p. 52).

O contexto no qual as imagens estão inseridas é o casamento, instituição heterossexual por excelência, o que acaba por naturalizar o amor heterossexual como única forma de amor legitimada. Dessa forma, “a 'unidade' do gênero é o efeito de uma prática reguladora, que busca uniformizar a identidade do gênero por via da heterossexualidade compulsória” (BUTLER, 2003, p. 57), garantindo a reprodução da 
matriz heterossexual.

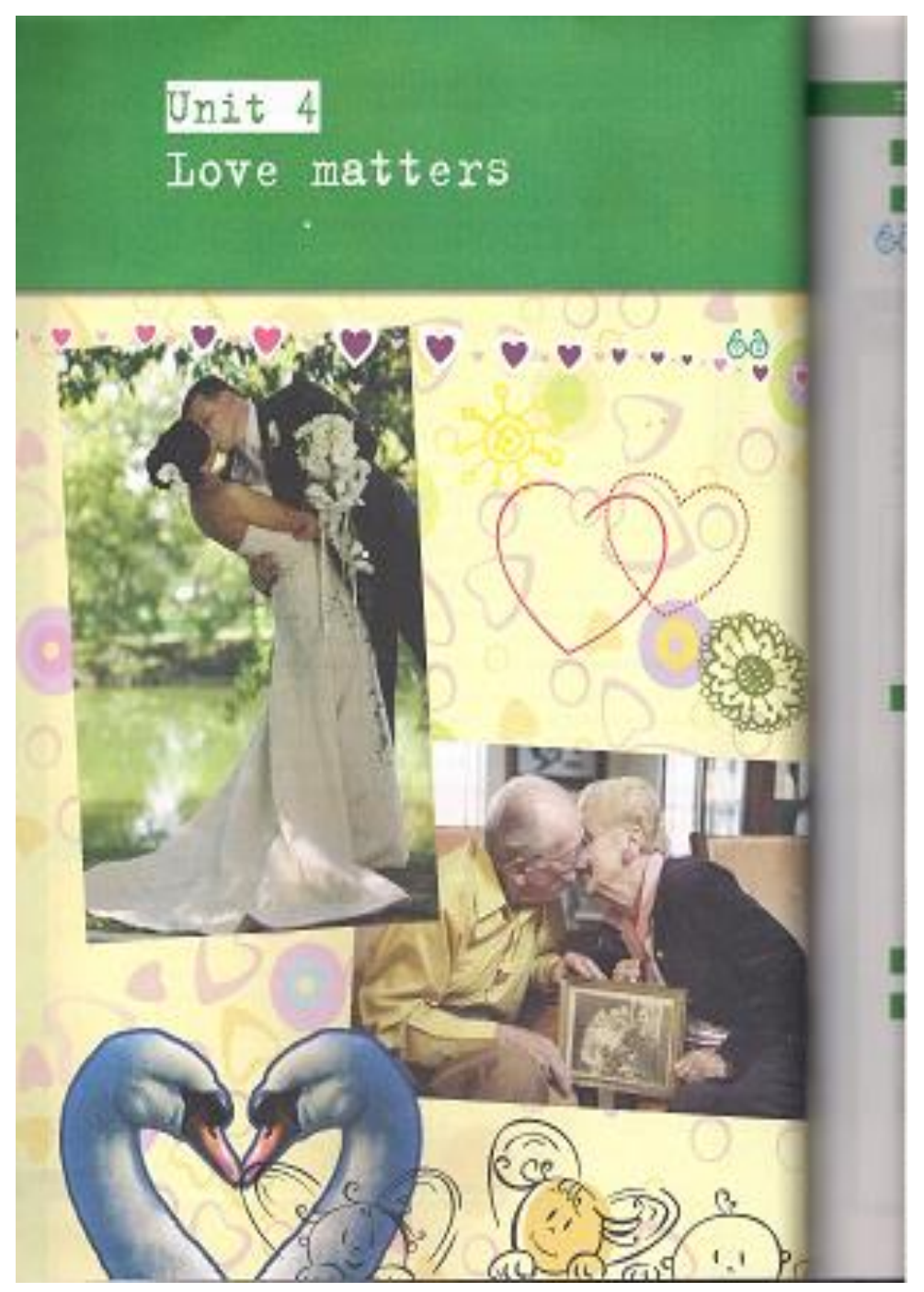

Fig. 1

Uma questão que merece destaque é o fato de um casal idoso estar representado em uma das imagens, ressaltando que o amor não tem idade. Contudo, as imagens privilegiam claramente o amor heterossexual, acabando por silenciar outras sexualidades, como a homoerótica.

O poema "Funeral blues" de W. H. Auden (DIAS, JUCÁ e FARIA, 2010a, p. 62) é proposto com o objetivo de abordar o gênero lírico e suas especificidades, como a estrutura das estrofes e a linguagem figurada, típica desse gênero. Antes da leitura do poema, menciona-se em uma nota dirigida aos/às alunos/as o fato de que o autor escreveu 
o poema para um amante que havia morrido. Salvo pela nota explicativa, o poema não faz qualquer alusão ao homoerotismo, fato esse corroborado pela falta do morfema marcador de gênero em inglês.

A presença do modo imperativo no poema sugere um diálogo entre pelo menos dois interlocutores. No "Manual do professor" (DIAS, JUCÁ e FARIA, 2010b), há uma orientação para que o/a professor/a passe uma cena do filme "Quatro casamentos e um funeral", na qual o poema é lido por um homem a seu amante falecido no dia do velório. Todavia, não se sugere que o tema do homoerotismo seja questionado. As atividades de compreensão também não problematizam o assunto, silenciando mais uma vez a voz homoerótica, que é completamente ignorada.

Embora não se perceba vozes legitimando uma expressão da sexualidade, um artigo, retirado da internet, a respeito dos aspectos neurofisiológicos do amor (DIAS, JUCÁ e FARIA, 2010a, p. 56) seria uma ótima oportunidade de problematizar o tema das sexualidades. Entretanto, o "Manual do professor" (DIAS, JUCÁ e FARIA, 2010b) não oferece sugestões para enfatizar o caráter universal desses aspectos, o que legitimaria todas as expressões da sexualidade.

O LD dissemina valores e crenças, produz discursos, constrói identidades e, muitas vezes, possui um papel autoritário no ensino de línguas, expressando, assim, a ideologia hegemônica. Portanto, o LD pode ter uma grande influência na construção das identidades sociais dos/as alunos/as, permitindo que algumas identidades sejam construídas e, consequentemente, legitimadas em detrimento de outras, aquelas que, no caso das identidades sexuais, não se enquadram na heterossexualidade compulsória (BUTLER, 2003).

\section{CONSIDERAÇÕES FINAIS}

A crescente visibilidade dos sujeitos homoeróticos contrasta com o aumento da violência homofóbica. Tal fato reflete na escola, pois sendo um espaço de socialização, ela dissemina preconceitos e discriminações que circulam através de diversos discursos, a saber, o curricular, o do $\mathrm{LD}$ e o dos/as próprios/as professores/as, que por desconhecimento sobre a sexualidade e sobre o homoerotismo, contribuem na 
perpetuação da homofobia.

Apesar dos esforços do Governo Federal e do Ministério da Educação para conter a homofobia nas escolas e eliminar aspectos preconceituosos em relação às sexualidades não heterossexuais dos LDs, estes continuam reforçando a matriz heterossexual e, por conseguinte, enfatizando a heterossexualidade como única forma de o sujeito viver sua sexualidade. A unidade aqui analisada caracteriza-se por uma visão heteronormativa do amor, excluindo qualquer outra expressão da sexualidade. Embora aborde o tema do homoerotismo em um poema, essa sexualidade não é problematizada. Conclui-se, portanto que, nesta unidade, a heterossexualidade é privilegiada em detrimento das outras expressões da sexualidade, ocasionando a marginalização destas.

\section{REFERÊNCIAS}

BAKHTIN,M. Estética da criação verbal. São Paulo: Martins Fontes, 2003.

BAKHTIN, M. M. Marxismo e filosofia da linguagem: problemas fundamentais do método sociológico na ciência da linguagem. São Paulo: Hucitec, 2004

BOURDIEU, P. A dominação masculina. Rio de Janeiro: Bertrand Brasil, 2003.

BRASIL. Programa Brasil sem homofobia. Brasília: Secretaria de Saúde, 2004. Disponível em: http://www.mj.gov.br/sedh/documentos/004_1_3.pdf. Acesso em 06 de Jun. de 2012.

BRASIL. Guia do livro didático PNLD 2012: Língua Estrangeira Moderna. Brasília: MEC, 2011. Disponível em: http://www.fnde.gov.br/index.php/pnld-guia-dolivrodidatico. Acesso em 03 de Dec. de 2012.

BUTLER, J. Corpos que pesam: sobre os limites discursivos do sexo. In: LOURO, G. L. (org.). O corpo educado: pedagogias da sexualidade. Belo Horizonte: Autêntica, 2001.

BUTLER, J. Problemas de Gênero: feminismo e subversão da identidade. Rio de Janeiro: Civilização Brasileira, 2003.

CALANTZIS, M. e COPE, B. Literacies. Cambridge: Cambridge University Press, 2012.

CASTRO, M. G., ABRAMOVAY, M. e SILVA, L. B. Juventudes e sexualidade. 
Brasília: UNESCO/MEC, 2004.

CORACINI, M. J. R. F. Apresentação. In: CORACINI, M. J. R. F. (org.). Interpretação, autoria e legitimação do livro didático. Campinas: Pontes, 1999.

DERRIDA, J. Gramatologia. São Paulo: Perspectiva, 2004.

DIAS, R., JUCÁ, L. e FARIA, R. Prime 2. São Paulo: Macmillan, 2010a.

DIAS, R.; JUCÁ, L. e FARIA, R. Teacher's guide. In: Prime 2. São Paulo: Macmillan, 2010b.

FAIRCLOUGH, N. Discurso e mudança social. Brasília: UNB, 2001.

FOUCAULT, M. História da sexualidade 1: a vontade de saber. Rio de Janeiro: Graal, 2001.

FRIDMAN, L. C. vertigens pós-moderna: configurações institucionais contemporâneas. Rio de Janeiro: Relume Dumará, 2000.

JUNQUEIRA, R. D. "Homofobia: um problema de todos". In: JUNQUEIRA, R. D. (org.). A diversidade sexual na educação: problematizações sobre a homofobia nas escolas. Brasília: UNESCO/MEC, 2009.

JUNQUEIRA, R. D. "Pedagogia do armário e currículo em ação: heteronormatividade, heterossexismo e homofobia no cotidiano escolar". In: MISKOLCI, R. e PELÚCIO, L. (orgs.). Discursos fora da ordem: sexualidades, saberes e direitos. São Paulo: Annablume, 2012.

KRESS, G. e VAN LEEUWEN, T. Reading images: the grammar of visual design. London/New York: Routledge, 2006.

KUMARAVADIVELU, D. "A Linguística Aplicada na era da globalização”. In MOITA LOPES, L. P. (org.) Por uma Linguística Aplicada (in)disciplinar. São Paulo: Parábola, 2006a.

KUMARAVADIVELU, D. Understanding language teaching: from method to postmethod. New Jersey/London: Lawrence Erlbaum Associates, $2006 \mathrm{~b}$.

LOURO, G. L. Teoria queer: uma política pós-identitária para a educação. Estudos Feministas, $n^{\circ} .2$, p. 541-553, 2001.

Belo Horizonte: Autêntica, 2004.

Um corpo estranho: ensaios sobre sexualidade e teoria queer.

MISKOLCI, R. Teoria queer: um aprendizado pelas diferenças. Belo Horizonte: 
Autêntica, 2012.

MOITA LOPES, L. P. Identidades fragmentadas: a construção discursiva de raça, gênero e sexualidade na escola.

ROJO, R. H. R. "Pedagogia dos multiletramentos: diversidade cultural e de linguagens na escola" In: ROJO, R. H. R. e MOURA, E. (orgs.) Multiletramentos na escola. São Paulo: Parábola, 2012. São Paulo: Mercado de letras, 2002.

RUFFOLO, D. V. Post-queer politics. Surrey: Ashgate, 2009.

SCHYERL, D. Práticas ideológicas na elaboração de materiais didáticos para a educação linguística. In: SCHYERL, D. e SIQUEIRA, S. Materiais didáticos para o ensino de línguas na contemporaneidade: contestações e proposições. Salvador: UFBA, 2012.

SILVA, T. T. Documentos de identidade: uma introdução às teorias do currículo. Belo Horizonte: Autêntica, 2003a.

A produção social da identidade e da diferença. In:

(org.). Identidade e diferença: a perspectiva dos Estudos Culturais. Belo Horizonte: Autêntica, 2003b.

TOMLINSON, B. "Glossary of basic terms for materials development in language teaching". In: TOMLINSON, B. (ed.). Materials development in language teaching. Cambridge: Cambridge University Press, 2011.

\section{O AUTOR}

Elio Marques de Souto Júnior, mestrando em Linguística Aplicada, UFRJ

E-mail: eliomsj@yahoo.com.br 